\title{
ON ALMOST STATISTICAL CONVERGENCE OF GENERALIZED DIFFERENCE SEQUENCES OF FUZZY NUMBERS
}

\author{
M. ET, Y. ALTIN and H. ALTINOK \\ Department of Mathematics, Firat University \\ 23119, Elazig-TURKEY \\ E-mail: mikailet@yahoo.com; yaltin23@yahoo.com \\ E-mail: hifsialtinok@yahoo.com
}

Received August 21, 2005; revised November 29, 2005

\begin{abstract}
The purpose of this paper is to introduce the concepts of almost statistical convergence and strongly almost convergence of generalized difference sequences of fuzzy numbers. We obtain some results related to these concepts. It is also shown that almost $\Delta_{\lambda}^{r}-$ statistical convergence and strongly almost $\Delta_{\lambda}^{r}$-convergence are equivalent for $\Delta^{r}$-bounded sequences of fuzzy numbers.
\end{abstract}

Key words: Fuzzy number, statistical convergence, difference sequence

\section{Introduction}

The concept of fuzzy sets and fuzzy set operations was first introduced by Zadeh [23] and subsequently several authors have discussed various aspects of the theory and applications of fuzzy sets such as fuzzy topological spaces, similarity relations and fuzzy orderings, fuzzy measures of fuzzy events, fuzzy mathematical programming. Matloka [15] introduced bounded and convergent sequences of fuzzy numbers and studied their some properties. Matloka [15] has shown that every convergent sequence of fuzzy numbers is bounded. Later on sequences of fuzzy numbers have been discussed by Nanda [17], Nuray and Savaş [18], Kwon [10], Savaş [20], Başarır and Mursaleen $([1,16])$ and many others.

The notion of statistical convergence was introduced by Fast [6] and Schoenberg [21], independently. Over the years and under different names statistical convergence has been discussed in the theory of fourier analysis, ergodic theory and number theory. Later on it was further investigated from the sequence space point 
of view and linked with summability theory by Fridy [7], Šalát [19], Tripathy [22], Connor [2] and many others. In recent years, generalizations of statistical convergence have appeared in the study of strong integral summability and the structure of ideals of bounded continuous functions on locally compact spaces. Statistical convergence and its generalizations are also connected with subsets of the Stone-Čech compactification of the natural numbers. Moreover, statistical convergence is closely related to the concept of convergence in probability.

In the present paper we introduce and examine the concepts of almost statistical convergence and strongly almost convergence of generalized difference sequences of fuzzy numbers. In section 2 we give a brief information about fuzzy numbers, the operator $\Delta^{r}$, the sequence $\lambda=\left(\lambda_{n}\right)$, statistical convergence and using the generalized difference operator $\Delta^{r}$ and the sequence $\lambda=\left(\lambda_{n}\right)$ we define the concepts of almost statistical convergence and strongly almost convergence of sequences of fuzzy numbers. In section 3 we establish some relations between strongly almost $\Delta_{\lambda}^{r}$-convergence and almost $\Delta_{\lambda}^{r}$-statistical convergence.

\section{Definitions and Preliminaries}

The definitions of statistical convergence and strong $p$-Cesàro convergence of a sequence of real numbers were introduced in the literature independently of one another and have followed different lines of development since their first appearence. It turns out, however, that the two definitions can be simply related to one another in general and are equivalent for bounded sequences. The idea of statistical convergence depends on the density of subsets of the set $\mathbb{N}$ of natural numbers. The density of a subset $E$ of $\mathbb{N}$ is defined by

$$
\delta(E)=\lim _{n \rightarrow \infty} \frac{1}{n} \sum_{k=1}^{n} \chi_{E}(k) \text { provided the limit exists, }
$$

where $\chi_{E}$ is the characteristic function of $E$. It is clear that any finite subset of $\mathbb{N}$ has zero natural density and $\delta\left(E^{c}\right)=1-\delta(E)$.

A sequence $\left(x_{k}\right)$ is said to be statistically convergent to $L$ if for every $\varepsilon>0$, $\delta\left(\left\{k \in \mathbb{N}:\left|x_{k}-L\right| \geq \varepsilon\right\}\right)=0$. In this case we write $S-\lim x_{k}=L$.

Let $C\left(\mathbb{R}^{n}\right)=\left\{A \subset \mathbb{R}^{n}: A\right.$ is compact and convex $\}$. The space $C\left(\mathbb{R}^{n}\right)$ has a linear structure induced by the operations $A+B=\{a+b: a \in A, b \in B\}$ and $\mu A=\{\mu a: a \in A\}$ for $A, B \in C\left(\mathbb{R}^{n}\right)$ and $\mu \in \mathbb{R}$. The Hausdorff distance between $A$ and $B$ in $C\left(\mathbb{R}^{n}\right)$ is defined as

$$
\delta_{\infty}(A, B)=\max \left\{\sup _{a \in A} \inf _{b \in B}\|a-b\|, \sup _{b \in B} \inf _{a \in A}\|a-b\|\right\} .
$$

It is well known that $\left(C\left(\mathbb{R}^{n}\right), \delta_{\infty}\right)$ is a complete metric space.

A fuzzy number is a function $X$ from $\mathbb{R}^{n}$ to $[0,1]$ which is normal, fuzzy convex, upper semi-continuous and the closure of $\left\{x \in \mathbb{R}^{n}: X(x)>0\right\}$ is compact. These properties imply that for each $0<\alpha \leq 1$, the $\alpha$-level set $X^{\alpha}=$ $\left\{x \in \mathbb{R}^{n}: X(x)>\alpha\right\}$ is a non-empty compact convex subset of $\mathbb{R}^{n}$, with support $X^{0}$. Let $L\left(\mathbb{R}^{n}\right)$ denote the set of all fuzzy numbers. The linear structure of $L\left(\mathbb{R}^{n}\right)$ induces the addition $X+Y$ and the scalar multiplication $\mu X, \mu \in \mathbb{R}$, in terms of $\alpha$-level sets, by 


$$
[X+Y]^{\alpha}=X^{\alpha}+Y^{\alpha}, \quad[\mu X]^{\alpha}=\mu X^{\alpha}
$$

for each $0<\alpha \leq 1$.

Define, for each $1 \leq q<\infty$,

$$
d_{q}(X, Y)=\left(\int_{0}^{1} \delta_{\infty}\left(X^{\alpha}, Y^{\alpha}\right)^{q} d \alpha\right)^{1 / q}
$$

and $d_{\infty}(X, Y)=\sup _{0 \leq \alpha \leq 1} \delta_{\infty}\left(X^{\alpha}, Y^{\alpha}\right)$. Clearly $d_{\infty}(X, Y)=\lim _{q \rightarrow \infty} d_{q}(X, Y)$ with $d_{q}(X, Y) \leq d_{s}(X, Y)$ if $q \leq s[3]$.

Throughout the paper, $d$ will denote $d_{q}$ with $1 \leq q \leq \infty$.

The famous space $\hat{c}$ of all almost convergent sequences was introduced by Lorentz [12] and several authors such as Duran [4], King [8] have studied almost convergent sequences. Maddox ([13],[14]) has defined $x$ to be strongly almost convergent to a number $L$ if

$$
\lim _{n} \frac{1}{n} \sum_{k=1}^{n}\left|x_{k+m}-L\right|=0, \quad \text { uniformly in } m .
$$

The idea of difference sequences for real numbers was first introduced by Kizmaz [9] and this concept was generalized by Et and Başarır [5].

Let $w$ be the set of all sequences of fuzzy numbers. The operator $\Delta^{r}: w \rightarrow w$ is defined by

$\left(\Delta^{0} X\right)_{k}=X_{k},\left(\Delta^{1} X\right)_{k}=\Delta^{1} X_{k}=X_{k}-X_{k+1},(k=0,1, \ldots), \Delta^{r}=$ $\Delta^{1} \circ \Delta^{r-1},(r \geq 2)$.

The generalized de la Vallée-Pousin mean is defined by

$$
t_{n}(x)=\frac{1}{\lambda_{n}} \sum_{k \in I_{n}} x_{k}
$$

where $\lambda=\left(\lambda_{n}\right)$ is a non-decreasing sequence of positive numbers such that $\lambda_{n+1} \leq$ $\lambda_{n}+1, \lambda_{1}=1, \lambda_{n} \rightarrow \infty$ as $n \rightarrow \infty$ and $I_{n}=\left[n-\lambda_{n}+1, n\right]$.

A sequence $x=\left(x_{k}\right)$ is said to be $(V, \lambda)$-summable to a number $L$ [11] if $t_{n}(x) \rightarrow L$ as $n \rightarrow \infty$. $(V, \lambda)$-summability reduces to $(C, 1)$ summability when $\lambda_{n}=n$ for all $n \in \mathbb{N}$.

Now we will extend the notions of strongly almost convergence and almost statistical convergence of sequences of real numbers to the idea of sequences of fuzzy numbers using the generalized difference operator $\Delta^{r}$ and the sequence $\lambda=\left(\lambda_{n}\right)$.

Definition 1 . Let $X=\left(X_{k}\right)$ be a sequence of fuzzy numbers. Then the sequence $X=\left(X_{k}\right)$ of fuzzy numbers is said to be almost $\Delta_{\lambda}^{r}$-statistically convergent to the fuzzy number $X_{0}$ if for every $\varepsilon>0$,

$$
\lim _{n \rightarrow \infty} \lambda_{n}^{-1}\left|\left\{k \in I_{n}: d\left(\Delta^{r} X_{k+i}, X_{0}\right) \geq \varepsilon\right\}\right|=0 \text {, uniformly in } i .
$$

In this case we write $X_{k} \rightarrow X_{0}\left(\hat{S}\left(\Delta_{\lambda}^{r}\right)\right)$ or $\hat{S}\left(\Delta_{\lambda}^{r}\right)-\lim X_{k}=X_{0}$.

The set of all almost $\Delta_{\lambda}^{r}$-statistically convergent sequences of fuzzy numbers is denoted by $\hat{S}\left(\Delta_{\lambda}^{r}\right)$. In the special case $\lambda_{n}=n$ for all $n \in \mathbb{N}$, we shall write $\hat{S}\left(\Delta^{r}\right)$ instead of $\hat{S}\left(\Delta_{\lambda}^{r}\right)$ and we said that $X$ is almost $\Delta^{r}$-statistically convergent to the fuzzy number $X_{0}$. 
Definition 2. Let $X=\left(X_{k}\right)$ be a sequence of fuzzy numbers and $p=\left(p_{k}\right)$ be a sequence of strictly positive real numbers. Then the sequence $X=\left(X_{k}\right)$ is said to be strongly almost $\Delta_{\lambda}^{r}$-convergent if there is a fuzzy number $X_{0}$ such that

$$
\lim _{n \rightarrow \infty} \lambda_{n}^{-1} \sum_{k \in I_{n}}\left[d\left(\Delta^{r} X_{k+i}, X_{0}\right)\right]^{p_{k}}=0, \text { uniformly in } i .
$$

In this case we write $X_{k} \rightarrow X_{0}\left(\left[w, p, \Delta_{\lambda}^{r}\right]\right)$. We shall use $\left[w, p, \Delta_{\lambda}^{r}\right]$ to denote the set of all strongly almost $\Delta_{\lambda}^{r}$-convergent sequences of fuzzy numbers. In the special case $\lambda_{n}=n$ for all $n \in \mathbb{N}$, and $p_{k}=1$ for all $k \in \mathbb{N}$, we shall write $\left[w, p, \Delta^{r}\right]$ and $\left[w, \Delta_{\lambda}^{r}\right]$, respectively, instead of $\left[w, p, \Delta_{\lambda}^{r}\right]$. If $X \in\left[w, p, \Delta^{r}\right]$ then we say that $X$ is strongly almost $\Delta^{r}$-Cesàro summable.

Definition 3. Let $X=\left(X_{k}\right)$ be a sequence of fuzzy numbers. Then the sequence $X=\left(X_{k}\right)$ of fuzzy numbers is said to be $\Delta^{r}$-bounded if the set $\left\{\Delta^{r} X_{k}: k \in \mathbb{N}\right\}$ of fuzzy numbers is bounded. By $\ell_{\infty}\left(\Delta^{r}\right)$ we shall denote the set of all $\Delta^{r}$-bounded sequences of fuzzy numbers.

\section{Main Results}

In this section we give some inclusion relations between strongly almost $\Delta_{\lambda}^{r}-$ convergence and almost $\Delta_{\lambda}^{r}$ - statistical convergence and show that they are equivalent for $\Delta^{r}$-bounded sequences of fuzzy numbers. We also study the inclusion $\hat{S}\left(\Delta^{r}\right) \subset \hat{S}\left(\Delta_{\lambda}^{r}\right)$ under certain restrictions on $\lambda=\left(\lambda_{n}\right)$.

Theorem 1. If $\left(X_{k}\right),\left(Y_{k}\right) \in \hat{S}\left(\Delta_{\lambda}^{r}\right)$ and $c \in \mathbb{R}$ then

i) $\hat{S}\left(\Delta_{\lambda}^{r}\right)-\lim c X_{k}=c \hat{S}\left(\Delta_{\lambda}^{r}\right)-\lim X_{k}$

ii) $\hat{S}\left(\Delta_{\lambda}^{r}\right)-\lim \left(X_{k}+Y_{k}\right)=\hat{S}\left(\Delta_{\lambda}^{r}\right)-\lim X_{k}+\hat{S}\left(\Delta_{\lambda}^{r}\right)-\lim Y_{k}$

Proof.

i) Let $\hat{S}\left(\Delta_{\lambda}^{r}\right)-\lim X_{k}=X_{0}, c \in \mathbb{R}$ and $\varepsilon>0$ be given. Then the proof follows from the following inequality:

$$
\begin{aligned}
& \lambda_{n}^{-1} \mid\left\{k \in I_{n}:\right.\left.d\left(\Delta^{r} c X_{k+i}, c X_{0}\right) \geq \varepsilon\right\} \mid \\
& \leq \lambda_{n}^{-1}\left|\left\{k \in I_{n}: d\left(\Delta^{r} X_{k+i}, X_{0}\right) \geq \frac{\varepsilon}{|c|}\right\}\right| .
\end{aligned}
$$

ii) Suppose that $\hat{S}\left(\Delta_{\lambda}^{r}\right)-\lim X_{k}=X_{0}$ and $\hat{S}\left(\Delta_{\lambda}^{r}\right)-\lim Y_{k}=Y_{0}$. By Minkowski's inequality we get

$$
d\left(\Delta^{r} X_{k+i}+\Delta^{r} Y_{k+i}, X_{0}+Y_{0}\right) \leq d\left(\Delta^{r} X_{k+i}, X_{0}\right)+d\left(\Delta^{r} Y_{k+i}, Y_{0}\right) .
$$

Therefore given $\varepsilon>0$ we have

$$
\begin{aligned}
& \lambda_{n}^{-1}\left|\left\{k \in I_{n}: d\left(\Delta^{r} X_{k+i}+\Delta^{r} Y_{k+i}, X_{0}+Y_{0}\right) \geq \varepsilon\right\}\right| \\
\leq & \lambda_{n}^{-1}\left|\left\{k \in I_{n}: d\left(\Delta^{r} X_{k+i}, X_{0}\right) \geq \frac{\varepsilon}{2}\right\}\right|+\lambda_{n}^{-1}\left|\left\{k \in I_{n}: d\left(\Delta^{r} Y_{k+i}, Y_{0}\right) \geq \frac{\varepsilon}{2}\right\}\right| .
\end{aligned}
$$


Hence $\hat{S}\left(\Delta_{\lambda}^{r}\right)-\lim \left(X_{k}+Y_{k}\right)=X_{0}+Y_{0}$

The following theorem shows that almost $\Delta_{\lambda}^{r}$-statistical convergence and strongly almost $\Delta_{\lambda}^{r}$-convergence are equivalent for $\Delta^{r}$-bounded sequences of fuzzy numbers.

Theorem 2. Let the sequence $\left(p_{k}\right)$ be bounded and $X=\left(X_{k}\right)$ be a sequence of fuzzy numbers. Then
i) $X_{k} \rightarrow X_{0}\left(\left[w, p, \Delta_{\lambda}^{r}\right]\right)$ implies $X_{k} \rightarrow X_{0}\left(\hat{S}\left(\Delta_{\lambda}^{r}\right)\right)$,
ii) $X \in \ell_{\infty}\left(\Delta^{r}\right)$ and $X_{k} \rightarrow X_{0}\left(\hat{S}\left(\Delta_{\lambda}^{r}\right)\right)$ imply $X_{k} \rightarrow X_{0}\left(\left[w, p, \Delta_{\lambda}^{r}\right]\right)$,
iii) $\hat{S}\left(\Delta_{\lambda}^{r}\right) \cap \ell_{\infty}\left(\Delta^{r}\right)=\left[w, p, \Delta_{\lambda}^{r}\right] \cap \ell_{\infty}\left(\Delta^{r}\right)$.

Proof.

i) Let $\varepsilon>0$ and $X_{k} \rightarrow X_{0}\left(\left[w, p, \Delta_{\lambda}^{r}\right]\right)$. Then we can write

$$
\begin{gathered}
\frac{1}{\lambda_{n}} \sum_{k \in I_{n}}\left[d\left(\Delta^{r} X_{k+i}, X_{0}\right)\right]^{p_{k}} \geq \frac{1}{\lambda_{n}} \sum_{\substack{k \in I_{n} \\
d\left(\Delta^{r} X_{k+i}, X_{0}\right) \geq \varepsilon}}\left[d\left(\Delta^{r} X_{k+i}, X_{0}\right)\right]^{p_{k}} \\
\geq \frac{1}{\lambda_{n}} \sum_{\substack{k \in I_{n} \\
d\left(\Delta^{r} X_{k+i}, X_{0}\right) \geq \varepsilon}} \varepsilon^{p_{k}} \geq \frac{1}{\lambda_{n}} \sum_{\substack{k \in I_{n} \\
d\left(\Delta^{r} X_{k+i}, X_{0}\right) \geq \varepsilon}} \min \left(\varepsilon^{h}, \varepsilon^{H}\right) \\
\geq \frac{1}{\lambda_{n}}\left|\left\{k \in I_{n}: d\left(\Delta^{r} X_{k+i}, X_{0}\right) \geq \varepsilon\right\}\right| \min \left[\varepsilon^{h}, \varepsilon^{H}\right],
\end{gathered}
$$

where $0<h=\inf p_{k} \leq p_{k} \leq \sup p_{k}=H<\infty$. Hence $X_{k} \rightarrow X_{0}\left(\hat{S}\left(\Delta_{\lambda}^{r}\right)\right)$.

ii) Suppose that $X \in \ell_{\infty}\left(\Delta^{r}\right)$ and $X_{k} \rightarrow X_{0}\left(\hat{S}\left(\Delta_{\lambda}^{r}\right)\right)$. Since $X \in \ell_{\infty}\left(\Delta^{r}\right)$, there is a constant $T>0$ such that $d\left(\Delta^{r} X_{k+i}, X_{0}\right) \leq T$. Given $\varepsilon>0$, we have

$$
\begin{aligned}
& \frac{1}{\lambda_{n}} \sum_{k \in I_{n}}\left[d\left(\Delta^{r} X_{k+i}, X_{0}\right)\right]^{p_{k}}=\frac{1}{\lambda_{n}} \sum_{\substack{k \in I_{n} \\
d\left(\Delta^{r} X_{k+i}, X_{0}\right) \geq \varepsilon}}\left[d\left(\Delta^{r} X_{k+i}, X_{0}\right)\right]^{p_{k}} \\
& +\frac{1}{\lambda_{n}} \sum_{\substack{k \in I_{n} \\
d\left(\Delta^{r} X_{k+i}, X_{0}\right)<\varepsilon}}\left[d\left(\Delta^{r} X_{k+i}, X_{0}\right)\right]^{p_{k}} \\
& \leq \frac{1}{\lambda_{n}} \sum_{d\left(\Delta^{r} X_{k+i}, X_{0}\right) \geq \varepsilon} \max \left(T^{h}, T^{H}\right)+\frac{1}{\lambda_{n}} \sum_{\substack{k \in I_{n} \\
d\left(\Delta^{r} X_{k+i}, X_{0}\right)<\varepsilon}} \varepsilon^{p_{k}} \\
& \leq \max \left(T^{h}, T^{H}\right) \frac{1}{\lambda_{n}}\left|\left\{k \in I_{n}: d\left(\Delta^{r} X_{k+i}, X_{0}\right) \geq \varepsilon\right\}\right|+\max \left(\varepsilon^{h}, \varepsilon^{H}\right) .
\end{aligned}
$$

Hence $X_{0} \in\left[w, p, \Delta_{\lambda}^{r}\right]$.

iii) Follows from (i) and (ii). 
Theorem 3. If a sequence $X=\left(X_{k}\right)$ is almost $\Delta^{r}$-statistically convergent to the fuzzy number $X_{0}$ and $\liminf _{n}\left(\lambda_{n} / n\right)>0$, then it is almost $\Delta_{\lambda}^{r}$-statistically convergent to $X_{0}$.

Proof. Given $\varepsilon>0$ we have

$$
\left|\left\{k \leq n: d\left(\Delta^{r} X_{k+i}, X_{0}\right) \geq \varepsilon\right\}\right| \supset\left|\left\{k \in I_{n}: d\left(\Delta^{r} X_{k+i}, X_{0}\right) \geq \varepsilon\right\}\right| .
$$

Therefore,

$$
\begin{aligned}
\frac{1}{n}\left|\left\{k \leq n: d\left(\Delta^{r} X_{k+i}, X_{0}\right) \geq \varepsilon\right\}\right| & \geq \frac{1}{n}\left|\left\{k \in I_{n}: d\left(\Delta^{r} X_{k+i}, X_{0}\right) \geq \varepsilon\right\}\right| \\
& \geq \frac{\lambda_{n}}{n} \cdot \frac{1}{\lambda_{n}}\left|\left\{k \in I_{n}: d\left(\Delta^{r} X_{k+i}, X_{0}\right) \geq \varepsilon\right\}\right| .
\end{aligned}
$$

Taking limit as $n \rightarrow \infty$ and using $\liminf _{n}\left(\lambda_{n} / n\right)>0$, we get that $X$ is $\Delta_{\lambda}^{r}$-statistically convergent to $X_{0}$.

Theorem 4. Let $0<p_{k} \leq q_{k}$ and $\left(q_{k} / p_{k}\right)$ be bounded. Then $\left[w, q, \Delta_{\lambda}^{r}\right] \subset$ $\left[w, p, \Delta_{\lambda}^{r}\right]$.

Proof. Let $X \in\left[w, q, \Delta_{\lambda}^{r}\right]$. Write $w_{k, i}=\left[d\left(\Delta^{r} X_{k+i}, X_{0}\right)\right]^{q_{k}}$ and $\mu_{k}=\frac{p_{k}}{q_{k}}$ so that $0<\mu<\mu_{k} \leq 1$ for each $k$.

We define the sequences $\left(u_{k, i}\right)$ and $\left(v_{k, i}\right)$ as follows:

Let $u_{k, i}=w_{k, i}$ and $v_{k, i}=0$ if $w_{k, i} \geq 1$, and let $u_{k, i}=0$ and $v_{k, i}=w_{k, i}$ if $w_{k, i}<1$. Then it is clear that for all $k \in \mathbb{N}$ we have $w_{k, i}=u_{k, i}+v_{k, i}, w_{k, i}^{\mu_{k}}=$ $u_{k, i}^{\mu_{k}}+v_{k, i}^{\mu_{k}}$. Now it follows that $u_{k, i}^{\mu_{k}} \leq u_{k, i} \leq w_{k, i}$ and $v_{k, i}^{\mu_{k}} \leq v_{k, i}^{\mu}$. Therefore

$$
\begin{aligned}
\lambda_{n}^{-1} \sum_{k \in I_{n}} w_{k, i}^{\mu_{k}} & =\lambda_{n}^{-1} \sum_{k \in I_{n}}\left(u_{k, i}^{\mu_{k}}+v_{k, i}^{\mu_{k}}\right) \\
& \leq \lambda_{n}^{-1} \sum_{k \in I_{n}} w_{k, i}+\lambda_{n}^{-1} \sum_{k \in I_{n}} v_{k, i}^{\mu}
\end{aligned}
$$

Since $\mu<1$, for each $n$ we have

$$
\begin{aligned}
\lambda_{n}^{-1} \sum_{k \in I_{n}} v_{k, i}^{\mu} & =\sum_{k \in I_{n}}\left(\lambda_{n}^{-1} v_{k, i}\right)^{\mu}\left(\lambda_{n}^{-1}\right)^{1-\mu} \\
& \leq\left(\sum_{k \in I_{n}}\left[\left(\lambda_{n}^{-1} v_{k, i}\right)^{\mu}\right]^{\frac{1}{\mu}}\right)^{\mu}\left(\sum_{k \in I_{n}}\left[\left(\lambda_{n}^{-1}\right)^{1-\mu}\right]^{\frac{1}{1-\mu}}\right)^{1-\mu} \\
& =\left(\lambda_{n}^{-1} \sum_{k \in I_{n}} v_{k, i}\right)^{\mu}
\end{aligned}
$$

by Hölder's inequality, and thus 


$$
\lambda_{n}^{-1} \sum_{k \in I_{n}} w_{k, i}^{\mu_{k}} \leq \lambda_{n}^{-1} \sum_{k \in I_{n}} w_{k, i}+\left(\lambda_{n}^{-1} \sum_{k \in I_{n}} v_{k, i}\right)^{\mu} .
$$

Hence $X \in\left[w, p, \Delta_{\lambda}^{r}\right]$

Theorem 5. $\left[w, \Delta_{\lambda}^{r}\right]_{\infty}=\ell_{\infty}\left(\Delta^{r}\right)$, where

$$
\left[w, \Delta_{\lambda}^{r}\right]_{\infty}=\left\{X=\left(X_{k}\right): \sup _{n, i} \lambda_{n}^{-1} \sum_{k \in I_{n}}\left[d\left(\Delta^{r} X_{k+i}, \overline{0}\right)\right]<\infty\right\} .
$$

Proof. Let $X \in\left[w, \Delta_{\lambda}^{r}\right]_{\infty}$. Then there exists a constant $K_{1}>0$ such that

$$
\frac{1}{\lambda_{1}} d\left(\Delta^{r} X_{1+i}, \overline{0}\right) \leq \sup _{n, i} \frac{1}{\lambda_{n}} \sum_{k \in I_{n}} d\left(\Delta^{r} X_{k+i}, \overline{0}\right) \leq K_{1} \text { for all } i
$$

and so we have $X \in \ell_{\infty}\left(\Delta^{r}\right)$.

Conversely, let $X \in \ell_{\infty}\left(\Delta^{r}\right)$. Then there exists a constant $K_{2}>0$ such that $d\left(\Delta^{r} X_{j}, \overline{0}\right) \leq K_{2}$ for all $j$, and so

$$
\frac{1}{\lambda_{n}} \sum_{k \in I_{n}} d\left(\Delta^{r} X_{k+i}, \overline{0}\right) \leq \frac{K_{2}}{\lambda_{n}} \sum_{k \in I_{n}} 1 \leq K_{2} \text { for all } k \text { and } i .
$$

Thus $X \in\left[w, \Delta_{\lambda}^{r}\right]_{\infty}$

\section{Conclusion}

Giving particular values to the sequence $\lambda=\left(\lambda_{n}\right), p$ and $r$ we obtain some sequence spaces which are the special cases of the sequence spaces that we have defined. The most of the results proved in the previous sections will be true for these spaces.

\section{Acknowledgment}

We wish to thank the referee for his several remarks and valuable suggestions that improved the presentation of the paper.

\section{References}

[1] M. Ba sarı $\mathrm{r}$ and M. Mursaleen. Some sequence spaces of fuzzy numbers generated by infi nite matrices. J. Fuzzy Math., 11(3), 757 - 764, 2003.

[2] J. Connor. A topological and functional analytic approach to statistical convergence. Applied and Numerical Harmonic Analysis, 403 - 413, 1999.

[3] P. Diamond and P. Kloeden. Metric spaces of fuzzy sets. Fuzzy Sets and Systems, 35, $241-249,1990$

[4] J.P. Duran. Infi nite matrices and almost convergence. Math. Zeit., 128, 75 - 83, 1972. 
[5] M. Et and M. Bassarı r. On some new generalized difference sequence spaces. Period. Math. Hungar., 35(3), 169 - 175, 1997.

[6] H. Fast. Sur la convergence statistique. Colloq. Math., 241 - 244, 1951.

[7] J.A. Fridy. On statistical convergence. Analysis, 5, 301 - 313, 1985.

[8] J.P. King. Almost summable sequences. Proc. Amer. Math. Soc., 16, 1219 - 1225, 1966.

[9] H. K1 zmaz. On certain sequence spaces. Canad. Math. Bull., 24, 169 - 176, 1981.

[10] J.S. Kwon. On statistical and p-Cesàro convergence of fuzzy numbers. Korean J. Comput. Appl. Math., 7(1), 195 - 203, 2000.

[11] L. Leindler. Über die Vallee-Pousinsche Summierbarkeit Allgemeiner Orthogonalreihen. Acta Math. Acad. Sci. Hungar., 16, 375 - 387, 1965.

[12] G.G. Lorentz. A contribution to the theory of divergent sequences. Acta Math., 80, 167 $-190,1948$.

[13] I.J. Maddox. Spaces of strongly summable sequences. Quart. J. Math., 18, 345 - 355, 1967.

[14] I.J. Maddox. A new type of convergence. Math. Proc. Camb. Phil. Soc., 83, 61 - 64, 1978.

[15] M. Matloka. Sequences of fuzzy numbers. BUSEFAL, 28, 28 - 37, 1986.

[16] M. Mursaleen and M. Ba sarı r. On some new sequence spaces of fuzzy numbers. Indian J. Pure Appl. Math., 34(9), 1351 - 1357, 2003.

[17] S. Nanda. On sequences of fuzzy numbers. Fuzzy Sets and Systems, 33, 123 - 126, 1989.

[18] F. Nuray and E. Sava s. Statistical convergence of fuzzy numbers. Math. Slovaca, 45(3), $269-273,1995$.

[19] T. Šalát. On statistically convergent sequences of real numbers. Math. Slovaca, 30, 139 $-150,1980$.

[20] E. Sava s. On strongly $\lambda$-summable sequences of fuzzy numbers. Inform. Sci., 125, 181 - 186, 2000.

[21] I.J. Schoenberg. The integrability of certain functions and related summability methods. Amer. Math. Monthly, 66, 361 - 375, 1959.

[22] B.C. Tripathy. Matrix transformations between some class of sequences. J. Math. Anal. Appl., 206, 448 - 450, 1997.

[23] L.A. Zadeh. Fuzzy sets. Information and Control, 8, 338 - 353, 1965.

\section{Apie beveik statistini apibendrintų skirtuminių fuzzy skaičių sekų konvergavimą}

M. Et, T. Altin, H. Altinok

Šio straipsnio tikslas supažindinti su beveik statistinio ir stipriai beveik statistinio apibendrintu fuzzy skaičių konvergavimo sąvokomis. Straipsnyje taip pat parodyta, kad beveik $\Delta_{\lambda}^{r}$ - statistinis konvergavimas ir stipriai beveik $\Delta_{\lambda}^{r}$ - statistinis konvergavimas yra ekvivalentūs $\Delta^{r}$ apribotoms fuzzy skaičių sekoms. 